\title{
Insulin Injection Practice and Injection Complications - Results from the Bangladesh Insulin Injection Technique Survey
}

\begin{abstract}
ABM Kamrul-Hasan, ${ }^{1}$ Ajit Kumar Paul, ${ }^{2}$ Mohammad Nurul Amin, ${ }^{3}$ Md Abu Jar Gaffar, ${ }^{4}$ Md Asaduzzaman, ${ }^{5}$ Mohammad Saifuddin, ${ }^{6}$ Marufa Mustari, ${ }^{7}$ Md Jahangir Alam, ${ }^{8}$ Mohammad Moin Shahid, ${ }^{9}$ KM Nahid-Ul-Haque, ${ }^{10}$ Muhammad Shah Alam, ${ }^{11}$ Md Motiur Rahman, ${ }^{12}$ Samir Kumar Talukder, ${ }^{13}$ Md Abdul Kader, ${ }^{10}$ Farhana Akter, ${ }^{14}$ Mohammad Abdul Hannan, ${ }^{15}$ Palash Kumar Chanda, ${ }^{1}$ Muhammed Abu Bakar ${ }^{16}$ and Shahjada Selim ${ }^{7}$

1. Department of Endocrinology, Mymensingh Medical College, Mymensingh, Bangladesh; 2. Department of Endocrinology, Mainamoti Medical College, Cumilla, Bangladesh; 3. Department of Endocrinology, Mugda Medical College, Dhaka, Bangladesh; 4. Department of Physiology, Naogaon Medical College, Naogaon, Bangladesh; 5. Department of Endocrinology, Shaheed Sheikh Abu Naser Specialized Hospital, Khulna, Bangladesh; 6. Department of Endocrinology, Dhaka Medical College, Dhaka, Bangladesh; 7. Department of Endocrinology, Bangabandhu Sheikh Mujib Medical University, Dhaka, Bangladesh; 8. Department of Endocrinology, Shaheed Ziaur Rahman Medical College, Bogura, Bangladesh; 9. Department of Endocrinology, Ad-Din Women's Medical College, Dhaka, Bangladesh; 10. Department of Endocrinology, Diabetic Association Medical College, Faridpur, Bangladesh, 11. Department of Medicine, Army Medical College, Cumilla, Bangladesh; 12. Department of Medicine, Rajshahi Medical College Hospital, Rajshahi, Bangladesh; 13. Department of Endocrinology, Rangpur Medical College, Rangpur, Bangladesh; 14. Department of Endocrinology, Chittagong Medical College, Chittagong, Bangladesh; 15. Department of Endocrinology, North East Medical College, Sylhet, Bangladesh; 16. Department of Endocrinology, Chattogram Maa-Shishu O General Hospital, Chittagong, Bangladesh
\end{abstract}

ntroduction: Diabetes mellitus is highly prevalent in Bangladesh and insulin is often needed for diabetes control. We lack sufficient data on the insulin injection technique and injection-related complications. Methods: The Bangladesh Insulin Injection Technique Survey (BIITS)

was conducted in 2018 in 18 centres throughout Bangladesh, involving 847 patients taking insulin for at least 6 months. All of the study subjects were interviewed using a structured questionnaire focusing on key insulin injection parameters. Results: The mean duration of insulin use by the study subjects was $3.84( \pm 4.05)$ years and the mean daily dose of insulin was $41( \pm 25)$ units. A total of $71.6 \%$ participants performed $\leq 2$ injections/day and premixed insulins were the most commonly used insulins. Mean glycated haemoglobin (HbA1C) was $9.5 \%$ $( \pm 2 \%)$. The proportion of syringe users and pen-device users was $68.1 \%$ and $31.9 \%$, respectively. Most of the participants injected in the abdomen and rotated the injection site(s). The majority lifted the skinfold correctly and inserted the needle at a 90-degree angle, but their dwell times after injections were not adequate. A total of 9.2\% of the subjects had injection-site lipohypertrophy (LH) and among them, $38.5 \%$ injected into the lesion. Patients with LH had higher HbA1C. Higher duration of insulin use ( $\geq 5$ years), reusing needles more often (>10 times), and injecting at angles other than 90 degrees were independent predictors of LH. The incidences of hypoglycaemia (36.7\%) and hyperglycaemia (67.4\%) were very high, and subjects with LH had higher chances of both hypoglycaemia and hyperglycaemia. Though most (92.1\%) of the patients received education about insulin injection initially, it was not repeated in the recent follow-up and was found to be ineffective. Conclusion: A huge gap between the insulin administration guidelines and current practice was observed in this study. Complications of insulin injections were also common. Healthcare providers should pay more attention to insulin education and re-evaluate injection practices from time to time.

\section{Keywords}

Diabetes, insulin injection, injection technique, lipohypertrophy, insulin education

Disclosures: ABM Kamrul-Hasan, Ajit Kumar Paul, Mohammad Nurul Amin, Md Abu Jar Gaffar, Md Asaduzzaman,

Mohammad Saifuddin, Marufa Mustari, Md Jahangir Alam, Mohammad Moin Shahid, KM Nahid-Ul-Haque, Muhammad Shah Alam,

Md Motiur Rahman, Samir Kumar Talukder, Md Abdul Kader, Farhana Akter, Mohammad Abdul Hannan, Palash Kumar Chanda,

Muhammed Abu Bakar and Shahjada Selim have no financial or non-financial relationships or activities to declare

in relation to this article.

Acknowledgment: The authors would like to thank the nurses and paramedics of the hospitals involved, who

assisted in data collection.

Review Process: Double-blind peer review.

Compliance with Ethics: All procedures were followed in accordance with the responsible committee on

human experimentation and with the Helsinki Declaration of 1975 and subsequent revisions. Informed consent

was received from the patients involved in this research survey.

Authorship: All named authors meet the criteria of the International Committee of Medical Journal Editors for authorship for this manuscript, take responsibility for the integrity of the work as a whole and have given final approval for the version to be published. Access: This article is freely accessible at touchENDOCRINOLOGY.com (C) Touch Medical Media 2020.

Received: 21 October 2019

Accepted: 8 January 2020

Published Online: 28 February 2020

Citation: European Endocrinology. 2020;16(1):41-8

Corresponding Author: ABM Kamrul-Hasan, Assistant Professor \& Head, Department of Endocrinology,

Mymensingh Medical College, Mymensingh-2200, Bangladesh. E: rangassmc@gmail.com 
Diabetes mellitus (DM) is a major global health problem. The national prevalence of diabetes in Bangladesh is $6.9 \%$ and is increasing at an alarming rate. ${ }^{1}$ Though the prevalence of type 1 diabetes mellitus (T1DM) is low in this area, the prevalence of gestational diabetes and young-onset type 2 DM (T2DM) is very high. ${ }^{1}$ Insulin is an indispensable component of diabetes management. ${ }^{2}$ Although the proportion of insulin users was $42.49 \%$ among patients with diabetes in a single-centre study, unfortunately, reliable statistics on insulin use are lacking in Bangladesh. ${ }^{3}$ The insulin injection technique plays an important role in glycaemic control, and poor injection technique is one of the important, modifiable reasons for inadequate glycaemic control. ${ }^{4}$ Insulin storage is also important as it may affect the potency of insulin, influencing its efficacy. ${ }^{5}$ Faulty injection technique is associated with injection-site complications including lipohypertrophy $(\mathrm{LH}) .{ }^{6}$ Moreover, improper handling of needles and other sharps used in insulin injection may increase the risk of accidental injury and transmission of blood-borne infections in the patients and their close contacts. ${ }^{7}$ Many guidelines have been published for ideal insulin injection practice, ${ }^{2,8}$ but unfortunately, there is a large gap between the guideline recommendations and actual practice of insulin use throughout the world. ${ }^{-13}$ Data from Bangladesh specifically are scarce in this aspect. Therefore, we conducted this nationwide survey - the Bangladesh Insulin Injection Technique Survey (BIITS) - to assess the current practice of insulin injection and complications of the injection in this area.

\section{Methods}

This cross-sectional survey was conducted in 18 centres delivering specialised diabetes care throughout Bangladesh from January to December 2018. Among the centres, six were endocrine out-patient departments (OPDS) of government hospitals, six were endocrine OPDs of non-government hospitals, and the remaining six were private endocrine clinics. All the centres participated voluntarily and without financial incentive.

Patients with diabetes (all subtypes) using insulin for at least 6 months by either syringe or pen were included in the sample. All the consenting subjects underwent a survey using an investigator-administered questionnaire focusing on the key insulin injection parameters. The questionnaire was based on the Injection Technique Questionnaire (ITQ) used in the Worldwide Injection Technique Questionnaire Study, with a little modification for convenience and better understanding in our settings..$^{10}$ Relevant socio-demographic data were also collected in face-to-face interviews with the help of a pre-tested data collection sheet. The investigators checked the insulin device used by the patient and examined their insulin injection site(s). The study subjects were asked to perform a dummy insulin injection in front of the investigator. The most recent glycated haemoglobin (HbA1c) results (within the previous 3 months of data collection) were collected from their treatment records.

Besides the demographic information of the subjects, the key insulin injection parameters, including the current injection practice, observed anomalies at injection sites, injection safety, injection technique education and blood glucose anomalies, were recorded in the data collection sheet.

The study was conducted according to Good Clinical Practice and the Declaration of Helsinki. Patient identity was kept confidential at all times. Subjects were neither placed at any health risk by the study nor treatment decisions were made based on it. In addition, no financial compensation was offered for participation. Ethics committee approval, although not required for such a survey, was nevertheless obtained whenever specifically requested by a centre. Informed consent was obtained from all subjects for being included in the study.

\section{Statistical analysis}

Descriptive statistics were performed using IBM SPSS Statistics for Windows, version 23.0. The continuous variables with normal distribution and without a normal distribution were expressed as mean \pm standard deviation and median, respectively. The categorical variables were presented as the percentage (number). Student's t-test and Chi-square test were performed for comparing the variables between different groups as appropriate. Multiple logistic regression analysis was performed to find out the important predictors of $L H$, hypoglycaemia, and hyperglycaemia. $P$ values $\leq 0.05$ were considered statistically significant.

\section{Results}

\section{General characteristics, insulin use and glycaemic control}

The study investigated a total of 847 insulin injectors. The mean duration of diabetes was $9.79( \pm 6.98)$ years and the mean duration of insulin use was $3.84( \pm 4.05)$ years. The mean insulin dose was $41( \pm 25)$ units, and $73.3 \%$ injected $<50$ units insulin per day. Though the majority (68.2\%) were self-injectors, a large proportion of the study subjects were dependent on family members (30.6\%) and paramedics (1.2\%) for insulin injections. More than $70.0 \%$ of participants received one or two injections per day. Premixed human insulin was the most commonly used insulin (46.4\%). The mean $\mathrm{HbA} 1 \mathrm{C}$ was $9.5 \%( \pm 2.0)$; the majority of participants $(94.1 \%)$ had uncontrolled diabetes (HbA1C $\geq 7 \%$ ) (Table 1).

\section{Insulin injection device use and reuse practice by the study population}

Syringes were used by $68.1 \%$ of the study subjects, whereas $31.9 \%$ used pen devices. Needles with $8 \mathrm{~mm}$ length were most commonly used (40.5\%), followed by $6 \mathrm{~mm}$ (31.8\%), $5 \mathrm{~mm}(14.4 \%), 4 \mathrm{~mm}(8.3 \%)$, and $12 \mathrm{~mm}$ (5.1\%). Most (98.8\%) of the syringe users reused the syringes, the frequency of reusing pen needles was $98.5 \%$ among the pen users. A total of $40.7 \%$ of the syringe users and $38.9 \%$ of the pen users reused the needles $>10$ times. The reasons given for reusing needles were to save money $(49.3 \%)$, for convenience $(39.7 \%)$, not knowing how many times needles can be used (21.9\%), to prevent excess waste (14.7\%), and unavailability of another syringe/pen needle (3.0\%).

\section{Handling insulin before and during injection}

Most of the study subjects (82.3\%) stored their insulin vials and pen devices in the non-freezing part of the refrigerator before starting their use, while $15.6 \%$ kept at room temperature, and 1.7\% kept insulins in an earthen pitcher with water seal. In between the injections, the frequency for the syringe users and pen users refrigerating the used insulins were $74.5 \%(430 / 577)$ and $72.6 \%(196 / 270)$, respectively. Of the 626 patients keeping insulins in the refrigerator in between injections, 429 of them (68.5\%) wait until the insulin reaches room temperature before injecting. Though 37.3\% never checked the expiry date of the insulins, only $4.5 \%(24 / 531)$ of those who checked the expiry date ever injected the date-expired insulins. Only $1.3 \%$ of the subjects injected through clothing. Though $78.3 \%(443 / 566)$ of the cloudy insulin users suspended those before injecting, only one subject $(0.2 \%, 1 / 443)$ tipped or rolled the insulin vials or pen devices for the recommended 20 times or more.

\section{Insulin injection site(s) and rotation patterns}

The frequency of single-site and multiple-site $(\geq 2)$ users for insulin injections were $35.1 \%$ and $64.9 \%$, respectively. The abdomen was the most frequent site of injection in both single-site (70.7\%) and multiple-site (59.8\%) users, followed by arm $(16.8 \%$ and $27.3 \%$ in single- and multiple-site users, respectively); thighs were less commonly 
Table 1: Population demographic and baseline characteristics

\begin{tabular}{|c|c|}
\hline Characteristic & $\mathrm{N}=847$ \\
\hline Age, mean years $\pm S D$ & $49.89 \pm 13.13$ \\
\hline Male & $369(43.6)$ \\
\hline Female & $478(56.4)$ \\
\hline \multicolumn{2}{|l|}{ Diabetes subtype } \\
\hline T1DM & $14(1.7)$ \\
\hline T2DM & $794(93.7)$ \\
\hline GDM & $31(3.7)$ \\
\hline Other* & $8(0.9)$ \\
\hline Years with diabetes, mean \pm SD & $9.79 \pm 6.98$ \\
\hline Years on insulin, mean \pm SD & $3.84 \pm 4.05$ \\
\hline \multicolumn{2}{|l|}{ Responsible for injection } \\
\hline Self & $578(68.2)$ \\
\hline Family member & 259 (30.6) \\
\hline Paramedic & $10(1.2)$ \\
\hline Total daily dose of insulin, mean units \pm SD & $41 \pm 25$ \\
\hline$<50$ units & $621(73.3)$ \\
\hline 50-99 units & $185(21.8)$ \\
\hline$\geq 100$ units & $41(4.8)$ \\
\hline \multicolumn{2}{|l|}{ Type of insulin used } \\
\hline Human premixed & $393(46.4)$ \\
\hline Human regular only & $82(9.7)$ \\
\hline NPH only & $2(0.2)$ \\
\hline $\mathrm{NPH}+$ human regular & $96(11.3)$ \\
\hline Basal analogue only & $55(6.5)$ \\
\hline Bolus analogue only & $14(1.7)$ \\
\hline Basal-bolus analogue & $47(5.5)$ \\
\hline Premixed analogue & $76(9.0)$ \\
\hline Basal analogue + human regular & $76(9.0)$ \\
\hline Analogue co-formulation & $6(0.7)$ \\
\hline \multicolumn{2}{|l|}{ Frequency of injections (per day) } \\
\hline 1 & $66(7.8)$ \\
\hline 2 & $540(63.8)$ \\
\hline 3 & $121(14.3)$ \\
\hline 4 & $113(13.3)$ \\
\hline$\geq 5$ & $7(0.8)$ \\
\hline $\mathrm{HbA} 1 \mathrm{c} \%$, mean $\pm \mathrm{SD}(\mathrm{n}=758)$ & $9.5 \pm 2.0$ \\
\hline$<7 \%$ & 45/758 (5.9) \\
\hline$\geq 7 \%$ & 713/758 (94.1) \\
\hline
\end{tabular}

Data are presented as $n(\%)$ unless otherwise stated.

* Specific types of diabetes due to other causes.

$G D M=$ gestational diabetes mellitus; $N P H=$ neutral protamine Hagedorn;

$S D=$ standard deviation; T1DM = type 1 diabetes mellitus; $T 2 D M=$ type 2 diabetes mellitus.

used (12.1\% of single-site users and $12.5 \%$ of multiple-site users) and buttocks were seldom used for injections. Most of the study subjects (84.5\%) practiced some form of rotation pattern of the injection sites.

\section{Insulin injection practice by the study population}

One-third (33.8\%) of the study subjects never cleaned the injection site before injection, whereas the frequencies of the subjects cleaning the injection sites always, often and sometimes were $43.2 \%, 3.3 \%$, and $19.7 \%$, respectively. Hexisol was the most commonly used (73.3\%) cleansing material followed by Savlon/Detol (13.9\%), alcohol swab (6.8\%) and water (6.1\%). Of the alcohol swab or disinfectant users, $57.3 \%(302 / 527)$ waited until the evaporation of those before injection, and $42.7 \%$ did not. A total of $89.7 \%$ (760/847) injected into a skinfold and $86.3 \%(656 / 760)$ of them lifted the skin correctly (with one or two fingers plus the thumb); $9.2 \%$ (70/760) released the skinfold immediately after inserting the needle into the skin, 60.8\% (462/760) after injecting the total dose of the insulin, and $30.0 \%$ (228/760) released after removing the needle at the completion of insulin injection. The angles of needle entry were 45 degrees in $27.7 \%$, 90 degrees in $64.6 \%$, and $\leq 30$ degrees in $4.8 \%$ of the subjects; $2.8 \%$ injected intra-dermally.

The dwell times of the needles after injections were $<5$ seconds in $34.7 \%$ (294/847), 5-10 seconds in 44.3\% (375/847), and >10 seconds in $7.7 \%$ (65/847); $13.3 \%$ (113/847) of the study subjects were not aware of the duration of needle dwell time after injections. The frequency of subjects with higher dwell times was higher among pen users than the syringe users (among the syringe users, dwell time was $<5$ seconds in $40.9 \%$, $5-10$ seconds in $38.3 \%$, and $>10$ seconds in $5.2 \%$; the frequencies were $21.5 \%, 57.0 \%$, and $13.0 \%$, respectively among the pen-users).

\section{Skipping insulin injections - frequency and causes}

More than half $(55 \%, 466 / 847)$ of the study subjects gave their history of skipping insulin injections; among them, 7.5\% (35/466) skipped several times a week, 66.1\% (308/466) skipped several times a month, and $26.4 \%$ (123/466) skipped insulin injection several times a year. When asked why the participants were skipping injections, the answers provided were as follows: forgot (58.4\%), was sick (24.2\%), just did not want to inject (23.8\%), too low glucose (20.6\%), did not eat (8.2\%), and other causes (4.7\%).

\section{Disposal practice of used sharps}

The majority (69.3\%) of the study subjects disposed of the used syringes/pen needles into the rubbish with the cap on, $12.4 \%$ into the rubbish without recapping, $7.8 \%$ into a home sharps container such as an empty bottle, $7.6 \%$ into a container specially made for used sharps, and $3.0 \%$ disposed the used sharps anywhere without recapping. Among those who disposed of the sharps into a container, $87.7 \%$ (114/130) put the containers into the rubbish.

\section{Injection site complications}

More than half (58.5\%) of the study subjects experienced pain during injection, whereas the frequencies of bleeding/bruising, insulin leakage from the injection site, and dribbling of insulin from needle tip after injection were $35.5 \%, 38.8 \%$, and $29.9 \%$, respectively. A total of $9.2 \%$ of the subjects had injection-site LH and among them, 38.5\% injected into the lesion (Table 2). Subjects with $\mathrm{LH}$ had higher HbA1C than those without $(10.0 \pm 2.2 \%$ versus $9.5 \pm 2.0 \%, p<0.001)$. The factors associated with painful injections and insulin leakage after injecting are highlighted in Table 3 and Table 4, respectively. The important predictors of the presence of $\mathrm{LH}$ in the study subjects are given in Table 5.

\section{Accidental injuries and blood-borne infections}

Accidental injury with diabetic sharps (needle or lancet) happened in $2.5 \%$ cases (the patient or others); $1.7 \%$ of the patients had a blood-borne infection(s).

\section{Insulin injection education and self-monitoring of blood glucose practices}

Most of the study subjects (92.1\%) reported that they had received education about insulin injection; the education was given by doctors (endocrinologists in $32.1 \%$ and other specialists or general physicians 
Table 2: Injection-site complications

\begin{tabular}{|c|c|c|}
\hline Variables & $\begin{array}{l}\text { Number of subjects } \\
(\mathrm{n} / \mathrm{N})\end{array}$ & Frequency (\%) \\
\hline Painful injections & $473 / 847$ & 55.8 \\
\hline \multicolumn{3}{|l|}{ Frequency of painful injections } \\
\hline Always & $9 / 473$ & 1.9 \\
\hline Often* & $40 / 473$ & 8.5 \\
\hline Sometimes $^{\dagger}$ & $413 / 473$ & 87.3 \\
\hline Almost never ${ }^{\ddagger}$ & $11 / 473$ & 2.3 \\
\hline Bleeding and/or bruising & $301 / 847$ & 35.5 \\
\hline \multicolumn{3}{|c|}{ Frequency of bleeding and/or bruising } \\
\hline Always & $3 / 301$ & 1.0 \\
\hline Often* & $10 / 301$ & 3.3 \\
\hline Sometimes $^{\dagger}$ & $254 / 301$ & 84.4 \\
\hline Almost never ${ }^{\ddagger}$ & $34 / 301$ & 11.3 \\
\hline $\begin{array}{l}\text { Insulin leakage from skin after } \\
\text { injection }\end{array}$ & $329 / 847$ & 38.8 \\
\hline \multicolumn{3}{|l|}{ Frequency of insulin leakage } \\
\hline Always & $2 / 329$ & 0.6 \\
\hline Often* & $9 / 329$ & 2.7 \\
\hline Sometimes $^{\dagger}$ & $258 / 329$ & 78.4 \\
\hline Almost never ${ }^{\ddagger}$ & $60 / 329$ & 18.2 \\
\hline $\begin{array}{l}\text { Dribble/leakage of insulin from the } \\
\text { needle tip after injection }\end{array}$ & $253 / 847$ & 29.9 \\
\hline \multicolumn{3}{|l|}{ Frequency of insulin dribble/leakage } \\
\hline Always & $4 / 253$ & 1.6 \\
\hline Often* & $36 / 253$ & 14.2 \\
\hline Sometimes $^{\dagger}$ & $185 / 253$ & 73.1 \\
\hline Almost never ${ }^{\ddagger}$ & $28 / 253$ & 11.1 \\
\hline Lipohypertrophy & $78 / 847$ & 9.2 \\
\hline \multicolumn{3}{|l|}{ Site of lipohypertrophy } \\
\hline Abdomen & $41 / 78$ & 52.6 \\
\hline Arm & $17 / 78$ & 21.8 \\
\hline Thigh & $18 / 78$ & 23.1 \\
\hline Buttock & $1 / 78$ & 1.3 \\
\hline Other site(s) & $1 / 78$ & 1.3 \\
\hline Inject into the lipohypertrophy & $30 / 78$ & 38.5 \\
\hline \multicolumn{3}{|c|}{ Reason of injecting into the lipohypertrophy } \\
\hline It is less painful & $5 / 30$ & 16.7 \\
\hline It is convenient & $4 / 30$ & 13.3 \\
\hline Just as a habit & $13 / 30$ & 43.3 \\
\hline Cannot explain & $8 / 30$ & 26.7 \\
\hline
\end{tabular}

*'Often' refers to several times a week.

t'Sometimes' refers to several times a month.

${ }^{{ }^{\prime}}$ 'Almost never' refers to several times a year. ${ }^{10}$

in $36.8 \%$ of cases) in most of the instances. Nurses (21.5\%), pharmacists (3.5\%), medicine shopkeepers (2.9\%), medical representatives (0.8\%), and other insulin-injecting patients with diabetes (2.4\%) were also insulin education providers to our study subjects. Such education was reviewed within the previous 6 months in only $39.6 \%$ of the patients. The injection sites were checked by the attending physicians in every visit only in $14.9 \%$ of the subjects, and $48.9 \%$ of study subjects could not remember whether their injection site(s) were ever checked. Almost half (49.6\%) of the patients never or rarely performed self-monitoring of
Table 3: Injection practices in 'pain-present' and 'pain-free' subgroups of the study subjects

\begin{tabular}{|c|c|c|c|c|}
\hline Parameter & $\begin{array}{l}\text { Total patients } \\
(\mathrm{N}=847)\end{array}$ & $\begin{array}{l}\text { Pain present } \\
(n=473)\end{array}$ & $\begin{array}{l}\text { Pain free } \\
(n=374)\end{array}$ & $\mathrm{p}^{*}$ \\
\hline \multicolumn{5}{|l|}{ Insulin device } \\
\hline Syringe & 68.1 & 73.2 & 61.8 & \multirow[t]{2}{*}{$<0.001$} \\
\hline Pen & 31.9 & 26.8 & 38.2 & \\
\hline \multicolumn{5}{|c|}{ Main site of injection } \\
\hline Abdomen & 63.6 & 60.3 & 67.9 & \multirow[t]{2}{*}{0.022} \\
\hline $\begin{array}{l}\text { Other than } \\
\text { abdomen }\end{array}$ & 36.4 & 39.7 & 32.1 & \\
\hline \multicolumn{5}{|l|}{ Needle reuse } \\
\hline$\leq 2$ times & 1.7 & 1.1 & 2.5 & \multirow[t]{4}{*}{0.001} \\
\hline $3-5$ times & 22.2 & 24.6 & 19.2 & \\
\hline 6-10 times & 35.4 & 30.4 & 41.9 & \\
\hline$>10$ times & 40.7 & 43.9 & 36.4 & \\
\hline \multicolumn{5}{|l|}{ Needle length } \\
\hline $4 \mathrm{~mm}$ & 8.3 & 11.8 & 3.7 & \multirow[t]{5}{*}{$<0.001$} \\
\hline $5 \mathrm{~mm}$ & 14.4 & 10.4 & 19.5 & \\
\hline $6 \mathrm{~mm}$ & 31.8 & 26.4 & 38.5 & \\
\hline $8 \mathrm{~mm}$ & 40.5 & 44.8 & 35.0 & \\
\hline $12 \mathrm{~mm}$ & 5.1 & 6.6 & 3.2 & \\
\hline \multicolumn{5}{|c|}{ Injects into a skinfold } \\
\hline Yes & 89.7 & 90.1 & 89.3 & \multirow[t]{2}{*}{0.401} \\
\hline No & 10.3 & 9.9 & 10.7 & \\
\hline \multicolumn{5}{|c|}{ Angle of needle entry } \\
\hline 90 degrees & 64.6 & 59.8 & 70.6 & \multirow[t]{2}{*}{0.001} \\
\hline $\begin{array}{l}\text { Other than } 90 \\
\text { degrees }\end{array}$ & 35.4 & 40.2 & 29.4 & \\
\hline \multicolumn{5}{|l|}{ Bleeding } \\
\hline Yes & 35.5 & 44.8 & 23.8 & \multirow[t]{2}{*}{$<0.001$} \\
\hline No & 64.5 & 55.2 & 76.2 & \\
\hline
\end{tabular}

Data are presented as \% unless otherwise stated.

* $p$-value by Chi-square test.

blood glucose (SMBG) and a few of the subjects performed SMBG for the recommended times.

\section{Hypoglycaemia and hyperglycaemia}

More than one-third (36.7\%) of the study subjects experienced hypoglycaemia (plasma glucose $<3.9 \mathrm{mmol} / \mathrm{L}$ with or without hypoglycaemic symptoms) for a median number of two times within the previous 6 months of the study; among them, 9.8\% experienced severe hypoglycaemia. A greater number of patients (67.4\%) experienced hyperglycaemic episodes (plasma glucose $>13.9 \mathrm{mmol} / \mathrm{L}$ ) in that period, and in $4.5 \%$ of the instances the hyperglycaemic episodes were severe. The factors contributing to the occurrence of hypoglycaemia and hyperglycaemia in the study are shown in Table 6.

\section{Discussion}

BIITS covered the entire country and all the sectors (government and private hospitals and specialist OPDs) of healthcare delivery systems in the country. The survey covered all the major aspects of insulin injections, including patient demographic characteristics, key insulin injection practices and parameters, complications, and education. A total of 847 patients from 18 centres participated in this study. Study subjects had been living with diabetes for an average of 9.8 years and had been 
Table 4: Factors affecting insulin leakage after injections

\begin{tabular}{|c|c|c|c|c|}
\hline Parameter & $\begin{array}{l}\text { Total patients } \\
(\mathrm{N}=847)\end{array}$ & $\begin{array}{l}\text { Leakage present } \\
(\mathrm{n}=329)\end{array}$ & $\begin{array}{l}\text { Leakage absent } \\
(\mathrm{n}=518)\end{array}$ & $p^{*}$ \\
\hline \multicolumn{5}{|c|}{ Insulin device } \\
\hline Syringe & 68.1 & 69.0 & 67.6 & \multirow[t]{2}{*}{0.705} \\
\hline Pen & 31.9 & 31.0 & 32.4 & \\
\hline \multicolumn{5}{|c|}{ Dwell time after injection } \\
\hline$<5 s$ & 34.7 & 39.5 & 31.7 & \multirow[t]{4}{*}{0.038} \\
\hline $5-10 s$ & 44.3 & 39.8 & 47.1 & \\
\hline$>10 s$ & 7.7 & 6.1 & 8.7 & \\
\hline $\begin{array}{l}\text { Not aware } \\
\text { how long }\end{array}$ & 13.3 & 14.6 & 12.5 & \\
\hline \multicolumn{5}{|c|}{ Needle length } \\
\hline $4 \mathrm{~mm}$ & 8.3 & 13.4 & 5.0 & \multirow[t]{5}{*}{$<0.001$} \\
\hline $5 \mathrm{~mm}$ & 14.4 & 17.0 & 12.7 & \\
\hline $6 \mathrm{~mm}$ & 31.8 & 22.5 & 37.6 & \\
\hline $8 \mathrm{~mm}$ & 40.5 & 45.3 & 37.5 & \\
\hline $12 \mathrm{~mm}$ & 5.1 & 1.8 & 7.1 & \\
\hline $\begin{array}{l}\text { TDD of } \\
\text { insulin, IU } \\
\text { mean } \pm \text { SD }\end{array}$ & $41 \pm 25$ & $45 \pm 29$ & $39 \pm 22$ & $<0.001$ \\
\hline
\end{tabular}

Data are presented as \% unless otherwise stated.

* $p$-value by Student's t-test or Chi-square test as applicable.

$I U=$ international unit; $S=$ seconds; $S D=$ standard deviation; $T D D=$ total daily dose.

Table 5: Binary logistic regression analysis for the predictors of lipohypertrophy in the study subjects

\begin{tabular}{|c|c|c|c|}
\hline Variables & Sub-groups & Odds ratio $(95 \% \mathrm{Cl})$ & $\mathrm{p}$ \\
\hline \multirow[t]{2}{*}{ Duration of insulin use } & $<5$ years & Referent & \\
\hline & $\geq 5$ years & $2.204(1.331-3.648)$ & 0.002 \\
\hline \multirow{2}{*}{$\begin{array}{l}\text { Number of injections/ } \\
\text { day }\end{array}$} & $\leq 2$ & Referent & \\
\hline & $>2$ & $0.797(0.427-1.490)$ & 0.477 \\
\hline \multirow{2}{*}{$\begin{array}{l}\text { Total daily dose of } \\
\text { insulin }\end{array}$} & $<50$ units & Referent & \\
\hline & $\geq 50$ units & $0.934(0.488-1.787)$ & 0.836 \\
\hline \multirow[t]{2}{*}{ Insulin device } & Pen device & Referent & \\
\hline & Syringe and vial & $1.637(0.850-3.152)$ & 0.141 \\
\hline \multirow[t]{2}{*}{ Needle length } & $\leq 6 \mathrm{~mm}$ & Referent & \\
\hline & $>6 \mathrm{~mm}$ & $0.607(0.343-1.075)$ & 0.087 \\
\hline \multirow[t]{2}{*}{ Needle reuse frequency } & $\leq 10$ times & Referent & \\
\hline & $>10$ times & $3.147(1.668-5.937)$ & $<0.001$ \\
\hline \multirow{2}{*}{$\begin{array}{l}\text { Use multiple sites for } \\
\text { injection }\end{array}$} & Yes & Referent & \\
\hline & No & $0.887(0.507-1.549)$ & 0.673 \\
\hline \multirow[t]{2}{*}{ Rotate injection site(s) } & Yes & Referent & \\
\hline & No & $1.082(0.524-2.236)$ & 0.832 \\
\hline \multirow[t]{2}{*}{ Angle of needle entry } & 90 degrees & Referent & \\
\hline & Not at 90 degrees & $2.203(1.322-3.672)$ & 0.002 \\
\hline \multirow[t]{2}{*}{ Injects into skinfold } & Yes & Referent & \\
\hline & No & 0.769 (0.309-1.917) & 0.574 \\
\hline \multirow[t]{2}{*}{ Injection education } & Yes & Referent & \\
\hline & No & $1.375(0.632-2.995)$ & 0.422 \\
\hline
\end{tabular}

$\mathrm{Cl}=$ confidence interval. using insulin for a mean of 3.8 years. These timeframes should reflect sufficient experience regarding diabetes management including insulin injection technique.

The mean daily dose of insulin in this study (41 units) was higher than the Indian ITQ Study (36.9 units) and another Indian study (33.36 units), but lower than the rest of the world (ROW; 50.2 units). ${ }^{10-2}$ The use of $<50$ insulin units/day by about three-quarters of the study subjects and their uncontrolled blood glucose indicates the inadequate adjustment of insulin dose in these patients. Olamoyegun et al. in Nigeria, found around $90 \%$ of insulin users were taking $\leq 40$ insulin units/day. ${ }^{13}$ The frequency of subjects taking a fewer number of injections (1 or 2) per day was higher, and the frequency of the subjects having at least four injections/day was lower, in this study than observed in the Indian- and the Worldwide-ITQ studies. These reflect greater use of premixed insulins and lesser use of basal-bolus insulin regimen by the subjects of the current study in comparison to those studies. ${ }^{10,11}$ Four daily injections of basal-bolus insulin are more costly and require more degrees of patient education and motivation than twice-daily premixed insulins. In developed countries, basal-bolus insulin is more acceptable than in developing and underdeveloped countries of the world.

Another important observation was that many (31.8\%) of the subjects in the current study were dependent on others (family members and paramedics) for injections, which may be a barrier to multiple daily insulin injections. Furthermore, the people who assist with injections may not always be available and this may lead to skipping insulin injections; also, injections by paramedics create extra costs for diabetes care. A similar picture was observed in a Nigerian study, in which $28.2 \%$ did not inject themselves. ${ }^{13}$ The global scenario is better in this aspect ( 98\% self-inject)..$^{10}$

The glycaemic control of the study subjects (mean HbA1c 9.5\%) was worse than the Indian ITQ (8.6\%) and global averages (8.5\%). ${ }^{10,11}$ Selim et al. in a previous study, found similar mean HbA1C (9.56\%) among Bangladeshi patients with T2DM, though more patients (18.9\%) had $\mathrm{HbA} 1 \mathrm{C}<7 \%$ in their study than ours $(5.9 \%){ }^{14}$ This is frustrating and alarming as insulin is considered to be the most potent weapon for diabetes control and in patients with T2DM; insulin is often used when oral anti-diabetic drugs fail to control diabetes. The study subjects were on insulin for a mean of 3.8 years, a long time for necessary adjustment and intensification of insulin dose. The reason behind this high $\mathrm{HbA} 1 \mathrm{C}$, despite sufficient time for insulin adjustment, must be discovered to get the benefit of insulin treatment in these patients.

Most of the subjects in the present study used insulin syringes; the use of pen devices was less frequent than in India and the ROW, including Nigeria. $10,11,13$ The pen devices are costly and many of our patients are unlikely to be able to afford them. The greater use of medium length $(6 \mathrm{~mm}$ and $8 \mathrm{~mm}$ ) needles and less use of shorter needles in this study are the reverse of ROW and Indian data. 10,11 Previous studies report a shifting trend from using longer-sized insulin needles to shorter ones worldwide, due to the increasing use of pen devices. ${ }^{10}$ Shorter needles are as effective as longer ones in terms of insulin delivery and confer some additional benefits, including reduction of injection pain and avoidance of intramuscular injections. ${ }^{2}$

Both frequency of needle reuse and the number of times needles were reused were much higher than in ROW, India and Nigeria. ${ }^{10-3}$ 
Table 6: Insulin injection-related factors influencing the frequency of hypoglycaemia and hyperglycaemia

\begin{tabular}{|c|c|c|c|c|c|}
\hline Variables & Category $\mathrm{N}=847$ & $\begin{array}{l}\% \text { with hypoglycaemia } \\
(n=311)\end{array}$ & $p^{*}$ & $\begin{array}{l}\text { \% with hyperglycaemia } \\
(\mathrm{n}=571)\end{array}$ & $p^{*}$ \\
\hline \multirow[t]{2}{*}{ Duration of insulin treatment (years) } & $<5(n=582)$ & 66.6 & \multirow{2}{*}{0.318} & 63.9 & \multirow{2}{*}{$<0.001$} \\
\hline & $\geq 5(n=265)$ & 33.4 & & 36.1 & \\
\hline \multirow[t]{2}{*}{$\mathrm{HbA} 1 \mathrm{c}(\%)$} & $<7(\mathrm{n}=45)$ & 5.8 & \multirow{2}{*}{1.000} & 4.3 & \multirow{2}{*}{0.008} \\
\hline & $\geq 7(n=713)$ & 94.2 & & 95.7 & \\
\hline \multirow[t]{2}{*}{ Diabetic complication(s) } & Absent $(n=395)$ & 40.8 & \multirow{2}{*}{0.010} & 44.7 & \multirow{2}{*}{0.106} \\
\hline & Present $(n=452)$ & 59.2 & & 55.3 & \\
\hline \multirow[t]{2}{*}{ Number of injections/day } & $\leq 2(n=606)$ & 70.4 & \multirow{2}{*}{0.581} & 71.3 & \multirow{2}{*}{0.871} \\
\hline & $>2(n=241)$ & 29.6 & & 28.7 & \\
\hline \multirow[t]{2}{*}{ Total daily dose of insulin (IU) } & $<50(n=621)$ & 72.7 & \multirow{2}{*}{0.748} & 70.2 & \multirow{2}{*}{0.004} \\
\hline & $\geq 50(n=226)$ & 27.3 & & 29.1 & \\
\hline \multirow[t]{2}{*}{ Insulin device } & Syringe $(n=577)$ & 70.1 & \multirow{2}{*}{0.360} & 70.9 & \multirow{2}{*}{0.015} \\
\hline & Pen $(n=270)$ & 29.9 & & 29.1 & \\
\hline \multirow[t]{2}{*}{ Needle length (mm) } & $\leq 6(n=461)$ & 55.0 & \multirow{2}{*}{0.830} & 45.0 & \multirow{2}{*}{$<0.001$} \\
\hline & $>6(n=380)$ & 45.0 & & 55.0 & \\
\hline \multirow[t]{2}{*}{ Main Injection site } & Abdomen $(n=539)$ & 57.9 & \multirow{2}{*}{0.009} & 62.0 & \multirow{2}{*}{0.170} \\
\hline & Others $(n=308)$ & 42.1 & & 38.0 & \\
\hline \multirow{2}{*}{ Rotate injection site(s) } & No $(n=131)$ & 16.7 & \multirow{2}{*}{0.490} & 15.6 & محס م \\
\hline & Yes $(n=716)$ & 83.3 & & 84.4 & $0.9 \angle 0$ \\
\hline Inject into a skinfold & Yes $(n=760)$ & 91.3 & م २०1 & 89.0 & 023 \\
\hline & No $(n=87)$ & 8.7 & 0.291 & 11.0 & 0.335 \\
\hline Angle of needle entry & 90 degrees $(n=547)$ & 61.1 & 0118 & 62.3 & 0055 \\
\hline & Other than 90 degrees $(n=300)$ & 38.9 & 0.118 & 37.7 & 0.055 \\
\hline Needle reuse & No $(n=11)$ & 1.9 & 0205 & 1.1 & 0351 \\
\hline & Yes $(n=836)$ & 98.1 & 0.225 & 98.9 & 0.351 \\
\hline Number of times needles reused & $\leq 10(n=496)$ & 56.4 & 0214 & 56.3 & 0011 \\
\hline & $>10(n=340)$ & 43.6 & 0.214 & 43.7 & 0.011 \\
\hline $\mathrm{LH}$ & Absent $(n=769)$ & 88.4 & ת & 89.0 & 808 \\
\hline & Present $(n=78)$ & 11.6 & 0.084 & 11.0 & 0.008 \\
\hline Injects into LH $(n=78)$ & No $(n=48)$ & 52.8 & 0166 & 55.6 & 037 \\
\hline & Yes $(n=30)$ & 47.2 & 0.166 & 44.4 & $0.03 /$ \\
\hline Skip injection(s) & Yes $(n=466)$ & 69.5 & & 65.3 & \\
\hline & No $(n=381)$ & 30.5 & $<0.001$ & 34.7 & $<0.001$ \\
\hline Education on injection technique & Yes $(n=780)$ & 96.8 & 1 & 92.6 & 0416 \\
\hline & No $(n=67)$ & 3.2 & $<0.001$ & 7.4 & 0.416 \\
\hline Education provider & Doctors $(n=537)$ & 59.8 & 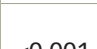 & 64.5 & ח \\
\hline & Others $(n=242)$ & 40.2 & $<0.001$ & 35.5 & $<0.001$ \\
\hline SMBG frequency & At least 1/day $(n=73)$ & 10.6 & & 7.9 & \\
\hline & At least 1/week $(n=354)$ & 42.4 & 0.223 & 42.6 & 0.509 \\
\hline & Never $(n=420)$ & 46.9 & & 49.6 & \\
\hline
\end{tabular}

* $p$-value comparing the column proportions by Chi-square test.

$H B A 1 C=$ glycated haemoglobin; $L H=$ lipohypertrophy; $S M B G=$ self-monitoring of blood glucose.

Reusing makes needles distorted and bent, as a result, injection-related complications including pain, bruising, local bleeding, infections and $\mathrm{LH}$ occur more frequently with needle reuse. ${ }^{2}$ Puder et al. suggested that using pen needles up to five times does not lead to needle tip deformity and does not increase pain or unpleasantness. ${ }^{15}$ Furthermore, such limited reuse could help save money for healthcare systems. ${ }^{15}$

Insulin vials and pens that are not in active use must be refrigerated, but not frozen. In places where a refrigerator is not available, such as in rural areas, the insulin vial may be kept in water in an earthen pitcher or wide-mouthed bottle after being air-tied in a plastic bag. Storing insulin at room temperature, which may exceed $30^{\circ} \mathrm{C}$ in summer in this area, may decrease the efficacy of insulin. ${ }^{2}$ Though the insulin storage practice was satisfactory in the majority, a good number of subjects in the current study stored insulin at room temperature before use. Olamoyegun et al. in Nigeria, had similar observations. ${ }^{13}$ Unfortunately, we found the majority of the pen users kept the pen devices with needles in the refrigerator in between injections. Pens should never be refrigerated with needles as this practice may cause insulin to precipitate in the needle and the needle may become blocked causing improper dosing. ${ }^{2}$ 
Cloudy insulins (premixed and neutral protamine Hagedorn [NPH]) must be suspended by proper tipping or rolling before the injection is given. Failure to re-suspend NPH and premixed insulins leads to significant variability in action profile, particularly the nocturnal plasma insulin concentration resulting in blood glucose variability, including hypoglycaemic episodes. ${ }^{2}$ Proper suspension practice was not observed in the majority of our study subjects; though the ROW scenario was better, the Indian ITQ Study had a similar picture. ${ }^{10,11}$

Though arms and thighs were more frequently used as a single injection site in this study than observed in India, ROW and Nigeria, the abdomen was the most frequent site of insulin injection used by our patients. ${ }^{10,11,13}$ The lower risk of intramuscular injection and more rapid absorption due to the presence of a thick subcutaneous fat layer have made the abdomen the first choice for insulin injection. Thigh injections carry a higher risk of intramuscular injection., 2,10,11 Systematic intra-site and inter-site rotation helps to maintain healthy injection sites, optimises insulin absorption and reduces the chance of LH. ${ }^{2}$ Most of the participants in the present study used multiple sites for injections and followed some form of rotation pattern while injecting; the rotation practice was similar to those observed in ROW, and better than Indian patients observed by Baruah et al. but not as good as the Nigerian insulin users. 10,12,13

Around two-thirds of the study subjects cleaned their injection site(s), a better picture than observed among previously reported Nigerian patients. ${ }^{13}$ The majority used disinfectants for the purpose and only a few used alcohol pads or water. The injection should always be given at a clean site with a clean hand. Though insulin can be injected provided the site is considered 'socially clean', the site should be thoroughly cleaned with either with alcohol swabs or with a cotton ball dipped in water always, especially if the injection site is found unclear. ${ }^{2}$ Almost half $(42.7 \%)$ of the study subjects who used alcohol pads and disinfectants did not wait until those evaporated before injecting; this practice may cause injection pain.

We observed the majority of the study subjects who injected into a skinfold lifted correctly, but most of them released the skinfold inappropriately. Pinching up skin decreases the chance of intramuscular injection. ${ }^{2,11}$ The angle of needle insertion was 90 degrees in the majority of the study subjects and only a few injected intradermally. Insulin must be injected into the subcutaneous fat layer for proper absorption; intradermal injections not only fail to deliver insulin at this site resulting in therapeutic ineffectiveness, but also increase the risk of local complications. ${ }^{2}$

Almost half of the patients skipped insulin injections, though frequent injection skipping was less common. A similar picture was observed in the ROW, and the main reasons for injection skipping in this study were also similar to the ROW study. ${ }^{10}$ Nigerian insulin users skipped injections less frequently than our study. ${ }^{13}$ The sharp disposal practice by our patients was poor, and worse than that observed in India. ${ }^{11}$ Such practice increases the risk of sharp injuries to anyone who comes near or handles the rubbish.

Pain was an important injection complication among the insulin users in the current study and pain was commonly associated with bleeding. Longer needles and higher frequency of needle reuse were associated with painful injections. Pen users had less painful injections due to the use of shorter needles. These findings were similar to the worldwideand the Indian ITQ Study results. ${ }^{16,17}$ Patient awareness of injection pain and discomfort has been studied extensively and is found to be related to three key factors: needle length, needle diameter and injection context. ${ }^{18,19}$ Subjects injecting into the abdomen experienced less frequent pain in our study, as was also observed by Heise et al. ${ }^{20}$

The ideal practice of keeping the needles under the skin for 10 seconds or longer after injecting was not followed by most of the subjects in this study. ${ }^{2}$ A shorter dwell time of the needles after injection is found to be associated with a higher frequency of insulin leakage from the site of injection by some researchers. It is also observed that the amount of leakage increased with increased dosage administered. ${ }^{21}$ There were similar observations in the present study. We also observed that smaller length needles were associated with a higher frequency of insulin leakage than the longer ones. Previous studies found no meaningful influence of needle length on the insulin leakage. ${ }^{21}$

Insulin $\mathrm{LH}$, which remains a serious local problem of insulin therapy, denotes a benign tumour-like swelling of fatty tissue at the injection site secondary to the lipogenic effect of insulin. ${ }^{22}$ The observed prevalence of $\mathrm{LH}$ in the current study (9.2\%) was lower than the previous studies done worldwide, which may be due to the shorter duration of insulin use in study subjects in the present study. ${ }^{12,16,17}$ The site distributions of LH (abdomen being the most common site) were similar to the Worldwide ITQ Study, though the most common sites of LH among Indian insulin injectors were thighs followed by arms and abdomen. 16,17 $^{-17}$ In the present study, longer duration of insulin use, higher frequency of needle reuse, and injecting at an oblique angle were found to be the important predictors of $\mathrm{LH}$. The presence of $\mathrm{LH}$ was associated with higher $\mathrm{HbA} 1 \mathrm{C}$ values, with a mean $\mathrm{HbA} 1 \mathrm{c} 0.5 \%$ higher in patients with $\mathrm{LH}$ than those without $\mathrm{LH}$ among Bangladeshi injectors. Previous investigators had similar observations. ${ }^{23-5}$ This is important in the setting of diabetes control because LH is a preventable complication of insulin injection, and only by its prevention can we lower HbA1C and reduce diabetes complications.

It is very important to provide education on insulin injection whenever a patient is prescribed with insulin, and such education should be repeated periodically for better therapeutic outcomes. Patients in the present study received such education at the beginning of their insulin treatment, though this was not repeated in the majority in recent months; similar scenarios were observed in the worldwide- and Indian-ITQ studies. 16,17 Thus the discrepancy in given education and current injection practice is the reflection of inadequacy and ineffectiveness of the education provided. Guidelines also recommended checking injection sites at least annually, and more frequently when the risk of $\mathrm{LH}$ and other injection-related complications are high. ${ }^{28,9}$ Unfortunately, around half of the patients in the present study never had their injection sites checked by their physicians as reported by the study subjects; this is alarming and the situation is worse than observed in India. ${ }^{17}$

The prevalence of both hypoglycaemia and hyperglycaemia among patients in the present study were high, even higher than the Worldwide ITQ Study and the Indian ITQ Study. ${ }^{16,17}$ The study subjects with diabetes complication(s), those who injected in abdomen, skipped injections, got education about insulin injection, and those who got insulin education from the doctors had higher frequency of hypoglycaemia than their counterparts. In addition to more stringent glycaemic control, other known risk factors for hypoglycaemia in diabetes include the use of insulin and insulin secretagogues, non-adherence to recommended diet and exercise, renal and hepatic impairment, longer duration of diabetes, alcohol ingestion and others. ${ }^{26}$ In contrast to our findings, rates of unexplained hypoglycaemia and glucose variability were found to be lower in the Worldwide ITQ Study when the abdomen is used 
exclusively as an injection site, but as one added the use of the limbs, the rates of both disorders increased..$^{16}$

The higher hypoglycaemic frequency among the insulin-educated subjects in our study is the reflection of the inadequacy and ineffectiveness of the education provided. We observed a higher frequency of hyperglycaemic episodes among the subjects with higher duration of diabetes, those using higher doses of insulin, among syringe users than pen users, those using longer needles, those with a higher frequency of need reuse, those with $\mathrm{LH}$ and whom inject into their $\mathrm{LH}$, those who skipped injections, and those who received insulin education from the doctors.

T2DM is a progressive disease with progressive loss of endogenous insulin secretion. Gradual up-titration of insulin dose is needed with increasing duration of diabetes in the majority of the patients; failure of proper insulin adjustment will result in uncontrolled diabetes. ${ }^{20}$ Subjects injecting insulin with pen devices demonstrated better glycaemic control in the previous studies, moreover, insulin analogues are more commonly used with pens, which provide better glycaemic efficacy in comparison to human insulin. ${ }^{27,28}$ Subjects using smaller needles had less chance of hyperglycaemia in our study; this may be due to using smaller needles in pen devices, which were associated with lower hyperglycaemia risk. Previous studies found higher frequencies of unexplained hypoglycaemia and glucose variability in those with $\mathrm{LH}$ and those injecting into $\mathrm{LH} .{ }^{16,17,25}$ We also observed significantly higher frequencies of hyperglycaemia in subjects with $\mathrm{LH}$ than without $\mathrm{LH}$. More subjects with $\mathrm{LH}$ had hypoglycaemic events than those without LH though the difference was not statistically significant. The worldwide- and Indian-ITQ studies found higher frequencies of unexplained hypoglycaemia and glucose variability in those with the incorrect rotation of sites, and with needle reuse. ${ }^{16,17}$
We observed no differences in hypo- and hyperglycaemic events between subjects who rotate injection sites and who do not. Though reusing needles did not impart a significant influence on the occurrences of hypo- and hyperglycaemic events in our study, subjects reusing needles $>10$ times had more chance of hyperglycaemic episodes. In contrast to our observation, receiving injection training from a trained person, e.g., a diabetes nurse, was found to be associated with less frequent unexpected hypoglycaemia and glucose variability in the Worldwide ITQ Study. ${ }^{16}$

\section{Limitations of the study}

This study has several limitations. The vital data input in this study involved recall by the patients (about events in recent months), which may have an inherent bias. Though during the interview the questions were translated to Bengali (the mother tongue of the study subjects) by the investigators, the questionnaire was in English. The study subjects were interviewed by multiple investigators, conferring the risk of observer bias. HbA1c was not measured by the same method in all the study centres. Nevertheless, this is the first multi-centre study which evaluated the insulin injection practices nationwide in Bangladesh and a fair number of patients were investigated. The study result may serve as a baseline for comparison of the injection practices in the future in this area.

\section{Conclusion}

Most of the patients in this area are not following the ideal insulin injection practice as per recommendations. The complications of insulin injection including LH were also high. The insulin education that was provided to most of them was found to be insufficient and almost ineffective. There is scope for improving these, lessening injection complications and improving glycaemic status. The results of the current study may serve as the backbone of the template on which different corrective strategies may be developed in the future. $\square$
1. International Diabetes Federation. IDF Diabetes Atlas Ninth Edition 2019. Available at: www.idf.org/our-activities/advocacyawareness/resources-and-tools/159-idf-diabetes-atlas-ninthedition-2019.html (accessed 28 January 2020)

2. Tandon N, Kalra S, Balhara YP, et al. Forum for injection technique and therapy expert recommendations, India: the Indian recommendations for best practice in insulin injection technique, 2017. Indian J Endocr Metab. 2017;21:600-17.

3. Siddiqui NI, Kamrul-Hasan M, Hossain MA, et al. Ramadan perspective epidemiology and education in diabetes (RAPEED) study. Mymensingh Med J. 2017;26:256-65.

4. Grassi G, Scuntero P, Trepiccioni R, et al. Optimizing insulin injection technique and its effect on blood glucose control. J Clin Transl Endocrinol. 2014:1:145-50.

5. Vimalavathini $R$, Gitanjali B. Effect of temperature on the potency \& pharmacological action of insulin. Indian J Med Res. 2009:130:166-9.

6. Deng $N$, Zhang $X$, Zhao $F$, et al. Prevalence of lipohypertrophy in insulin-treated diabetes patients: a systematic review and meta-analysis. J Diabetes Investig. 2018;9:536-43.

7. Majumdar A, Sahoo J, Roy G, Kamalanathan S. Improper sharp disposal practices among diabetes patients in home care settings: need for concern? Indian J Endocrinol Metab. 2015;19:420-5.

8. Frid AH, Kreugel G, Grassi G, et al. New insulin delivery recommendations. Mayo Clin Proc. 2016;91:1231-55.

Spollett G, Edelman SV, Mehner P, et al. Improvement of insulin injection technique: examination of current issues and recommendations. Diabetes Educ. 2016:42:379-94.

10. Frid $A H$, Hirsch $\sqcup$, Menchior $A R$, et al. Worldwide injection technique questionnaire study: population parameters and injection practices. Mayo Clin Proc. 2016:91:1212-23.

11. Kalra S, Mithal A, Sahay R, et al. Indian injection technique study: population characteristics and injection practices Diabetes Ther. 2017:8:637-57.

12. Baruah MP, Kalra S, Bose S, Deka J. An audit of insulin usage and insulin injection practices in a large Indian cohort. Indian Endocr Metab. 2017;21:443-52.

13. Olamoyegun MA, Akinlade AT, Ala OA. Audit of insulin prescription patterns and associated burden among diabetics in a tertiary health institution in Nigeria. Afri Health $\mathrm{SC}$. 2018; 18:852-64.

14. Selim S, Pathan F, Saifuddin M, et al. The challenge of prope glycaemic control among patients with type 2 diabetes in Bangladesh. SJDEM. 2016;6:16-20

15. Puder J, Atar M, Muller B, et al. Using insulin pen needles up to five times does not affect needle tip shape nor increase pain five times does not affect needle tip shape nor increas
intensity. Diabetes Res Clin Pract. 2005:67:119-23.

16. Frid $A H$, Hirsch $L$, Menchior $A R$, et al. Worldwide injection technique questionnaire study: injecting complications and the role of the professional. Mayo Clin Proc. 2016;91:1224-30.

17. Kalra S, Mithal A, Sahay $R$, et al. Indian injection technique study: injecting complications, education, and the health care professional. Diabetes Ther. 2017;8:659-72.

18. Brady KA, Avner JR, Khine H. Perception and attitude of providers towards pain and anxiety associated with pediatric vaccine injection. Clin Pediatr. 2011;50:140-3.

19. Diamond S, Matok I. Pharmacists' anticipated pain compared to experienced pain associated with insulin pen injection and fingertip. Can J Diabetes. 2011:35:282-6.

20. Heise T, Nosek L, Dellweg S, et al. Impact of injection speed and volume on perceived pain during subcutaneous injections into the abdomen and thigh: a single-centre, randomized controlled trial. Diabetes Obes Metab. 2014:16:971-6.

21. Wittmann A, Köver J, Kralj N, et al. Insulin leakage value in relation to pen needle length and administered dose after subcutaneous injection. Diabetes Technol Ther. 2010;12:587-90

22. Radermecker RP, Piérard GE, Scheen AJ. Lipodystrophy reactions to insulin: effects of continuous insulin infusion and new insulin analogs. Am I Clin Dermatol. 2007;8:21-8.

23. Vardar B, Kizilci S. Incidence of lipohypertrophy in diabetic patients and a study of influencing factors. Diabetes Res Clin Pract. 2007;77:231-6.

24. Saez-de Ibarra L, Gallego F. Factors related to lipohypertrophy in insulin-treated diabetic patients: role of educational intervention. Pract Diab Int. 1998:15:9-11.

25. Blanco M, Hernández MT, Strauss KW, Amaya M. Prevalence and risk factors of lipohypertrophy in insulin-injecting patients with diabetes. Diabetes Metab. 2013;39:445-53.

26. American Diabetes Association. 6. Glycemic targets: standards of medical care in diabetes-2019. Diabetes Care. 2019;42(Suppl. 1): S61-70.

27. Singh $R$, Samuel $C$, Jacob Jj. A comparison of insulin pen devices and disposable plastic syringes - simplicity, safety, convenience and cost differences. Eur Endocrinol. 2018; 14:47-51

28. Xie L, Zhou S, Pinsky BW, et al. Impact of initiating insulin glargine disposable pen versus vial/syringe on real-world glycemic outcomes and persistence among patients with type 2 diabetes mellitus in a large managed care plan: a claims database analysis Diabetes Technol Ther. 2014:16:567-75. 